\title{
Caveolin 1 knockdown inhibits the proliferation, migration and invasion of human breast cancer BT474 cells
}

\author{
RUI WANG ${ }^{1}, \mathrm{ZHI} \mathrm{LI}^{1}, \mathrm{HUI} \mathrm{GUO}^{1}, \mathrm{WEI} \mathrm{SHI}^{1}, \mathrm{YUE} \mathrm{XIN}^{1}$, WEILONG CHANG $^{2}$ and TAO HUANG $^{1}$ \\ Departments of ${ }^{1}$ Breast and Thyroid Surgery and ${ }^{2}$ General Surgery, Union Hospital, Tongji Medical College, \\ Huazhong University of Science and Technology, Wuhan, Hubei 430022, P.R. China
}

Received October 10, 2013; Accepted February 13, 2014

DOI: $10.3892 / \mathrm{mmr} .2014 .2018$

\begin{abstract}
Previous studies have demonstrated that caveolin 1 acts as a tumor suppressor in breast cancer, however, few studies have demonstrated that caveolin 1 also serves as a tumor promoter in breast cancer. In the present study, caveolin 1 small interfering RNA was used to knock down caveolin 1 expression in order to investigate the association between caveolin 1 and the proliferation and metastatic abilities of human breast cancer BT474 cells. The results revealed that cell proliferation, migration and invasion were attenuated by caveolin 1 knockdown in BT474 cells. Furthermore, caveolin 1 knockdown in BT474 cells arrested cells in the G0/G1 phase and decreased the number of cells in the $\mathrm{S}$ phase. In addition, caveolin 1 knockdown decreased the activation of the extracellular signal-regulated kinase $1 / 2$ pathway and inhibited the expression of cell cycle-associated proteins (cyclin D1, c-Fos and $\beta$-catenin), whilst the expression of E-cadherin was increased. Furthermore, the protein expression of matrix metalloproteinase-2, -9 and -1 was also inhibited by caveolin 1 knockdown. In combination, these results demonstrated that caveolin 1 knockdown had a tumor suppressing effect on BT474 cells.
\end{abstract}

\section{Introduction}

Breast cancer is one of most common types of malignancy that occurs in females around the world. In the United States, in 2013, 232,340 females were diagnosed with breast cancer and $\sim 39,620$ breast cancer-associated mortalities were estimated (1). In addition, breast cancer is the most common cause of cancer-associated mortality in females in China. Accurate prognosis and effective treatments against breast cancer

Correspondence to: Professor Tao Huang, Department of Breast and Thyroid Surgery, Union Hospital, Tongji Medical College, Huazhong University of Science and Technology, 1277 Jiefang Road, Wuhan, Hubei 430022, P.R China

E-mail: huangtaowh@gmail.com

Key words: caveolin 1, breast cancer, BT474, proliferation, migration, invasion require a more in depth understanding of the cellular and molecular mechanisms involved in breast cancer development and progression.

Caveolin 1, a 21-24 kDa membrane protein, is a major structural component of caveolae, which are identifiable plasma membrane invaginations. It has been suggested that caveolin 1 functions as a scaffold protein for signal transduction, transformation, endocytosis, cholesterol homeostasis, the cell cycle, cell migration and invasion (2-4).

Emerging evidence has demonstrated that caveolin 1 serves as a tumor suppressor protein and knockdown of caveolin 1 activates anchorage-independent growth of transformed cells (5). However, caveolin 1 has also been demonstrated to have a tumor promoting role in prostate cancer, renal cancer and esophageal squamous cell carcinoma (6-8), suggesting that whether caveolin 1 acts as tumor suppressor or facilitator depends upon specific tumor types.

The potential function of caveolin 1 in the development and progression of breast cancer remains unclear. In human breast cancer MCF-7 cells, the overexpression of caveolin 1 is associated with the suppression of cell growth and inhibition of migration and invasion (9). However, there is evidence that caveolin 1 also acts as a tumor promoter in breast cancer. It has been reported that the depletion of caveolin 1 decreased migration, polarization and focal adhesion in MDA-MB-231 cancer cells (basal-like phenotype) (10). This is consistent with another study, which demonstrated that caveolin 1 is highly associated with the breast cancer basal-like phenotype (11). In the present study, human breast cancer BT474 cells were used to analyze the role of caveolin 1 in BT474 cells. It was hypothesized that caveolin 1 may serve as a tumor promoter in BT474 cells, leading to tumor growth, migration and invasion.

\section{Materials and methods}

Cell lines and reagents. The human breast cancer BT474 cell line was purchased from American Type Cell Culture (Manassas, VA, USA). The cells were cultured in RPMI-1640 medium supplemented with $10 \%$ fetal bovine serum (FBS; HyClone Laboratories, South Logan, UT, USA) and 1\% penicillin/streptomycin (Beyotime Biotech, Nanjing, China) in the presence of $5 \% \mathrm{CO}_{2}$ and at $37^{\circ} \mathrm{C}$. Antibodies [anti-caveolin 1, anti-p-extracellular signal-regulated kinase 1/2 (ERK1/2) and anti-ERK1/2] were purchased from Cell Signaling Technology, Inc. (Beverly, 
MA, USA). Anti-matrix metalloproteinase 1 (MMP-1), anti-MMP-2 and E-cadherin were purchased from Epitomics, Inc. (Burlingame, CA, USA). Anti-MMP-9, anti-cyclin D1 and anti-GAPDH were purchased from Santa Cruz Biotechnology, Inc. (Santa Cruz, CA, USA). Anti-c-Fos and anti- $\beta$-catenin were purchased from Abcam (Cambridge, MA, USA).

Small interfering RNA (siRNA). The target siRNA against human caveolin 1 (si-h-Cav-1) was designed and constructed by Guangzhou Ribio Biotech Co., Ltd (Guangzhou, China). The sequence was as follows: si-h-Cav-1, forward 5'-GCA UCAACUUGCAGAAAGAdTdT-3' and reverse 3'-dTdTCGUA GUUGAACGUCUUUCU-5'.

Prior to transfection the medium was replaced with penicillin/streptomycin-free RPMI-1640 complete medium. BT474 cells were then transfected with si-h-Cav-1 or negative control siRNA (siCon) using Lipofectamine ${ }^{\mathrm{TM}} 2000$ (Invitrogen Life Technologies, Carlsbad, CA, USA).

Western blot analysis. The cells were seeded in six-well plates and were allowed to grow to $60-80 \%$ confluence. The concentration of the total protein was determined using the bicinchoninic acid protein assay kit (Beyotime Biotech). SDS-PAGE (Beyotime Biotech) was used to separate the total protein, prior to transfer onto PVDF membranes (Millipore, Billerica, MA, USA). The membranes were blocked with 5\% milk in $0.1 \%$ Tris-buffered saline with Tween ${ }^{\circledR} 20$ (BioSharp, Seoul, South Korea) (TBST) for $1 \mathrm{~h}$ at $37^{\circ} \mathrm{C}$, prior to being incubated with primary antibody overnight at $4^{\circ} \mathrm{C}$ followed by three washes in $0.1 \%$ TBST for $5 \mathrm{~min}$. The membranes were then incubated in horseradish peroxidase-conjugated anti-rabbit secondary antibody (1:5,000; Boster Biological Technology, Co., Ltd., Wuhan, Hubei, China) for $1 \mathrm{~h}$ at $37^{\circ} \mathrm{C}$, following washing in $0.1 \%$ TBST for 5 min three times. An enhanced chemiluminescence Substrate Reagent kit (Thermo Fisher Scientific, Waltham, MA, USA) was added and the band intensity of the blot was quantified using a gel imager (Bio-Rad, Hercules, CA, USA). GAPDH was used as an internal standard.

Immunofluorescence analysis. The cells were seeded in six-well plates at 50-60\% confluence, prior to being treated for $48 \mathrm{~h}$ with si-h-Cav-1 or siCon, respectively. The cells were washed with cold phosphate-buffered saline (PBS) twice and then fixed in $4 \%$ paraformaldehyde at room temperature for $10 \mathrm{~min}$. The cells were subsequently washed twice in PBS and the slides were blocked with $1 \%$ bovine serum albumin (BSA; Amresco, Solon, OH, USA) in $0.1 \%$ PBS with Tween 20 with $0.3 \mathrm{M}$ glycine for $30 \mathrm{~min}$. The slides were then incubated with anti-caveolin 1 antibody for $2 \mathrm{~h}$ at room temperature. Fluorescein isothiocyanate-conjugated goat-anti-rabbit immunoglobulin $\mathrm{G}$ was used to detect the primary antibody for $1 \mathrm{~h}$ at room temperature in the dark and DAPI $(0.5 \mu \mathrm{g} / \mathrm{ml}$; Sigma-Aldrich, St. Louis, MO, USA) was used to label nuclei for $3 \mathrm{~min}$ at room temperature in the dark. Image capture and processing were performed using an Olympus IX71 fluorescence microscope (Olympus, Tokyo, Japan).

Cell proliferation assay and chemotherapy sensitivity assay. To assess cell proliferation and chemotherapy sensitivity to doxorubicin (Dox; Sigma-Aldrich), the Cell Counting kit-8 (CCK-8) assay (Dojindo Lab., Kumamoto, Japan) was used in accordance with the manufacturer's instructions. The cells were seeded in 96-well plates at a density of $5 \times 10^{3}$ cells/well. The culture medium was removed and $100 \mu \mathrm{l}$ diluted CCK- 8 (1:9; diluted in RPMI-1640 medium) was added to each well, and the cells were incubated at $37^{\circ} \mathrm{C}$ for $1.5 \mathrm{~h}$. The optical density was then detected at a wavelength of $450 \mathrm{~nm}$ using a microplate reader (Thermo Fisher Scientific).

Colony formation assay. For the colony formation assay, following transfection with si-h-Cav-1 or siCon, the cells were seeded in six plates $\left(3 \times 10^{2} /\right.$ well). The cells were cultured for 9 days prior to being stained with crystal violet, and then images of the cells were captured and analyzed for colony formation.

Transwell migration and invasion assays. The upper transwell chamber ( $8 \mu \mathrm{m}$ pore size; Corning Inc., Union City, CA, USA), coated (Sigma-Aldrich; invasion assay) or not coated with ECM gel (migration assay), was covered by $5 \times 10^{4}$ cells in $200 \mu \mathrm{l}$ medium containing $0.1 \%$ BSA. The lower chamber was then filled with $200 \mu \mathrm{l}$ RPMI-1640 medium containing 30\% FBS (HyClone Laboratories). The cells were then cultured at $37^{\circ} \mathrm{C}$ and $5 \% \mathrm{CO}_{2}$ for $22 \mathrm{~h}$, prior to being fixed with $70 \%$ ethanol and stained with $0.1 \%$ crystal violet. The number of cells were counted in multiple random fields using the Olympus IX71 fluorescence microscope (Olympus).

Flow cytometric analysis. For the cell cycle assay, cells $\left(1-2 \times 10^{5}\right)$ were collected and washed twice with PBS and centrifuged at $1,500 \mathrm{x} g$ for $5 \mathrm{~min}$. The cells were then resuspended and fixed in $70 \%$ ethanol in PBS overnight at $-20^{\circ} \mathrm{C}$. Fixed cells were washed twice with PBS and centrifuged at $1,500 \mathrm{x} \mathrm{g}$ for $5 \mathrm{~min}$ prior to being resuspended in $500 \mu \mathrm{l}$ propidium iodide (50 $\mu \mathrm{g} / \mathrm{ml}$; BioSharp, Seoul, South Korea) with RNase A (50 $\mu \mathrm{g} / \mathrm{ml}$; Amresco). The cells were then incubated at $4^{\circ} \mathrm{C}$ for $30 \mathrm{~min}$ in the dark and subsequently analyzed using flow cytometry (BD Biosciences, Franklin Lakes, NJ, USA).

Statistical analysis. Statistical analysis of all the data were performed using the SPSS 11.0 software (SPSS, Inc., Chicago, IL, USA). The results are presented as the mean \pm standard deviation. Student's t-test was used to evaluate significant differences and $\mathrm{P}<0.05$ was considered to indicate a statistically significant difference.

\section{Results}

Stable knockdown of caveolin 1 in human breast cancer BT474 cells. In order to investigate the role of caveolin 1 in human breast cancer, BT474 cells were transfected with si-h-Cav-1 to knockdown caveolin 1 expression or siCon as a control. The successful knockdown of caveolin 1 was confirmed using western blotting (Fig. 1A) and immunofluorescence analysis (Fig. 1B).

Effect of caveolin 1 knockdown on cell growth, migration and invasion in BT474 cells. To examine whether caveolin 1 knockdown affects the cell growth of BT474 cells, BT474 
A
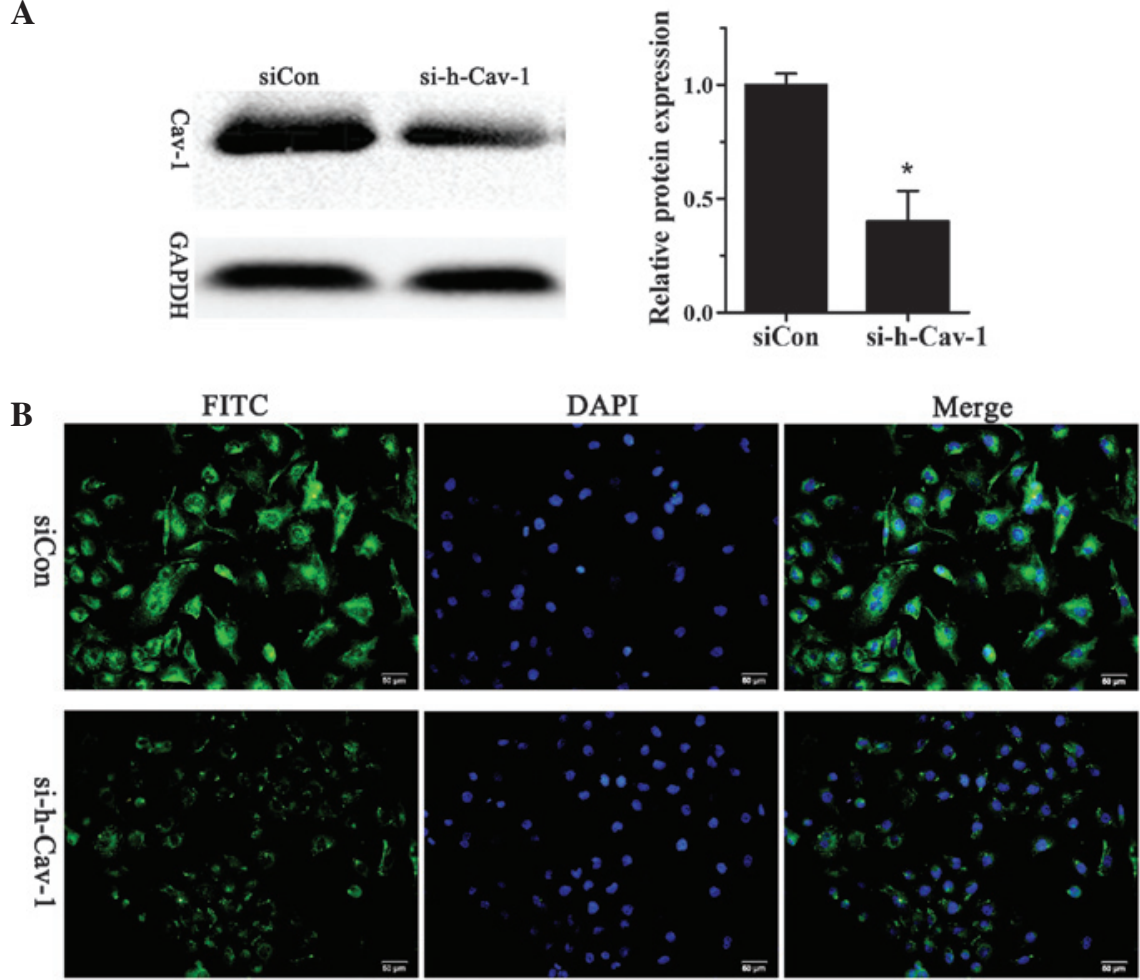

Figure 1. Stable knockdown of caveolin 1 in breast cancer cells. (A) Knockdown efficiency of si-h-Cav-1 or siCon was detected using western blot analysis. The protein expression levels of caveolin 1 subsequent to caveolin 1 knockdown in BT474 cells were significantly lower compared with the siCon group. (B) Immunofluorescence was performed to validate the expression and location of caveolin 1. Caveolin 1 knockdown decreased caveolin 1 expression in the cell membrane of BT474 cells. Error bars represent the mean \pm standard deviation. Experiments were performed in triplicate. ${ }^{*} \mathrm{P}<0.05$, compared with siCon. Cav-1, caveolin 1; si-h-Cav-1, small interfering RNA against human caveolin 1; siCon, control siRNA; FITC, fluorescein isothiocyanate.

cells were transfected with si-h-Cav-1 or siCon in 96-well plates. Cell proliferation was evaluated using the CCK-8 kit at different time points $(24,48,72$ and $96 \mathrm{~h})$. The results demonstrated that cell growth significantly decreased 72 and $96 \mathrm{~h}$ after caveolin 1 knockdown in BT474 cells compared with cells transfected with siCon (Fig. 2A). Transwell assays were performed to detect the effect of caveolin 1 knockdown on the migration and invasion of BT474 cells. The results demonstrated that caveolin 1 knockdown in BT474 cells attenuated their metastatic ability (Fig. 2B).

Effect of caveolin 1 knockdown in BT474 cells on colony formation, the cell cycle and Dox-induced cell death. To further confirm the impact of caveolin 1 knockdown on cell growth, the cell cycle was analyzed using flow cytometry. The results demonstrated that the number of BT474 cells in G0/G1 phase increased, whilst the number of cells in the $\mathrm{S}$ phase decreased following caveolin 1 knockdown (Fig. 3A). The efficiency of cell colony formation was analyzed and it was found to decrease in caveolin 1 knockdown BT474 cells (Fig. 3B). The cells were treated with Dox for $12 \mathrm{~h}$, prior to being transfected with si-h-Cav-1 or siCon for $36 \mathrm{~h}$. BT474 cells in the si-h-Cav-1 group demonstrated higher sensitivity to the Dox treatment compared with cells in the siCon group (Fig. 3C).

Effect of caveolin 1 knockdown in BT474 cells on the expression of proteins involved in the cell cycle, migration and invasion. BT474 cells were further investigated from a mechanistic perspective. Caveolin 1 knockdown reduced the activation of the ERK1/2 pathway (Fig. 4A) and decreased the expression of proteins involved in the cell cycle, including cyclin D1, c-Fos and $\beta$-catenin (Fig. 4B). Caveolin 1 knockdown in BT474 cells also led to the upregulation of E-cadherin (Fig. 4B). Furthermore, the protein expression of the MMP family (MMP-2, MMP-9 and MMP-1) was also investigated and it was found that MMP expression decreased with caveolin 1 knockdown (Fig. 4C).

\section{Discussion}

Caveolin 1 has been demonstrated to have a suppressing and promoting role in pancreatic cancer, lung cancer, esophageal squamous cell carcinoma, renal cell carcinoma, prostate cancer and melanoma (6-8,12-14). Previous studies have found that patients with a high caveolin 1 expression have more progressive diseases, and caveolin 1 has been demonstrated to have tumor promoting and pro-survival functions in more advanced disease stages $(15,16)$. By contrast, several studies have also revealed that caveolin 1 functions as a tumor suppressor in breast cancer, which has been confirmed in breast cancer MCF7 cells and several animal models $(17,18)$. However, there is also evidence that caveolin 1 serves as a tumor promoter in breast cancer (19). In the present study, it was demonstrated that caveolin 1 had a tumor promoting role in BT474 cells. Knockdown of caveolin 1 resulted in the suppression of cell proliferation, migration and invasion of BT474 cells. 


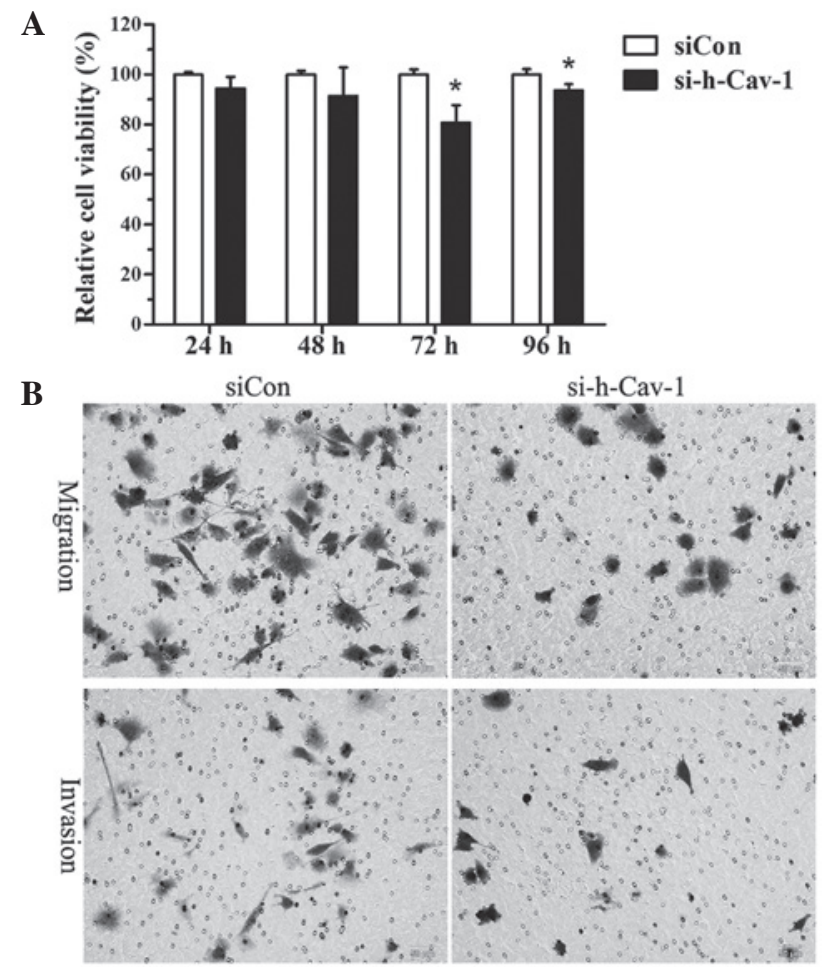

Figure 2. Effect of caveolin 1 knockdown on cell growth, migration and invasion of BT474 cells. (A) Cell growth was assessed using the Cell Counting kit-8 assay. Cell proliferation was reduced by caveolin 1 knockdown in BT474 cells at 72 and $96 \mathrm{~h}$, whilst it was promoted in cells treated with siCon at 72 and $96 \mathrm{~h}$. (B) Migration and invasion were evaluated using the transwell assay. Caveolin 1 knockdown markedly attenuated the metastatic abilities of BT474 cells $(\mathrm{P}<0.05$; magnification, $\mathrm{x} 200)$. Error bars represent the mean \pm standard deviation. Experiments were performed in triplicate. "P $<0.05$, compared with siCon si-h-Cav-1, small interfering RNA against human caveolin 1; siCon, control siRNA.

A

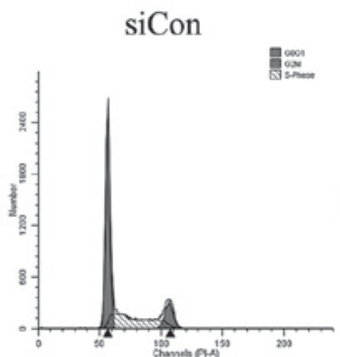

B

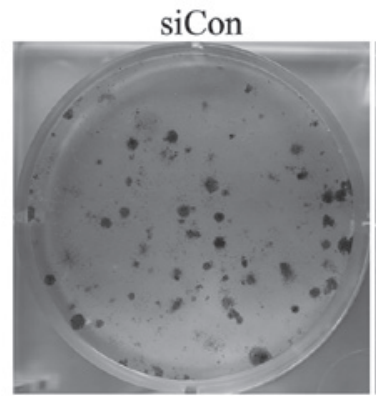

si-h-Cav-1

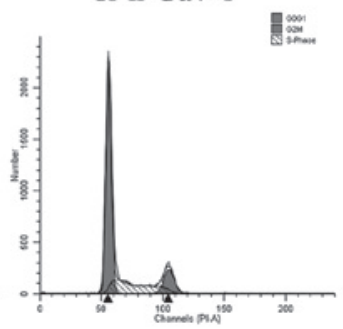

si-h-Cav-1

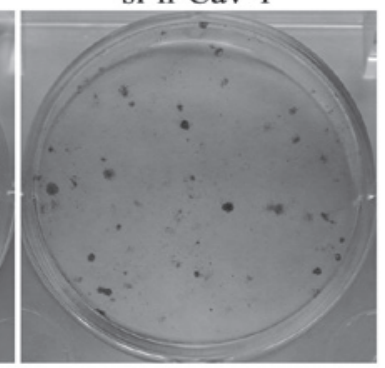

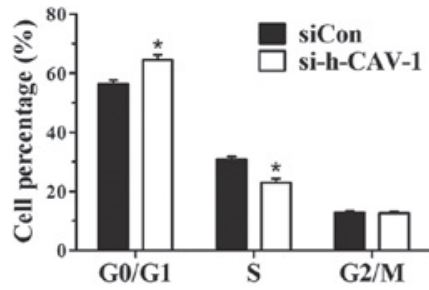

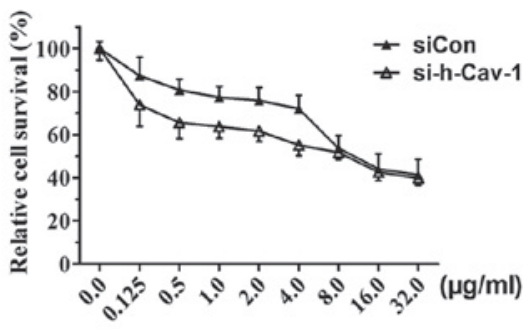

Figure 3. Effect of caveolin 1 knockdown on the cell cycle, colony formation and sensitivity to Dox. (A) Cell cycle was analyzed using flow cytometry. Caveolin 1 knockdown in BT474 cells arrested cells in the G0/G1 phase and decreased cells in the S phase. (B) Colony formation in cells treated with siCon and si-h-Cav-1. The efficiency of colony formation was reduced by $\sim 50 \%$ in caveolin 1 BT474 cells ( $\mathrm{P}<0.05)$. (C) Cell survival in cells treated with siCon and si-h-Cav-1, subjected to different Dox concentrations. Caveolin 1 knockdown decreased the resistance of BT474 cells to Dox treatment. Error bars represent the mean \pm standard deviation. Experiments were performed in triplicate. ${ }^{*} \mathrm{P}<0.05$, compared with siCon. Dox, doxorubicin; si-h-Cav-1, small interfering RNA against human caveolin 1; siCon, control siRNA.

It has been demonstrated that caveolin 1 is able to negatively regulate cell proliferation. Knockdown of caveolin 1 resulted in a decrease in the number of cells in the G0/G1 phase population and an increase in the number of cells in the $\mathrm{S}$ phase population, through driving the expression of cyclin D1, an essential factor in the G1/S transition and in tumor formation (20-22). 
A
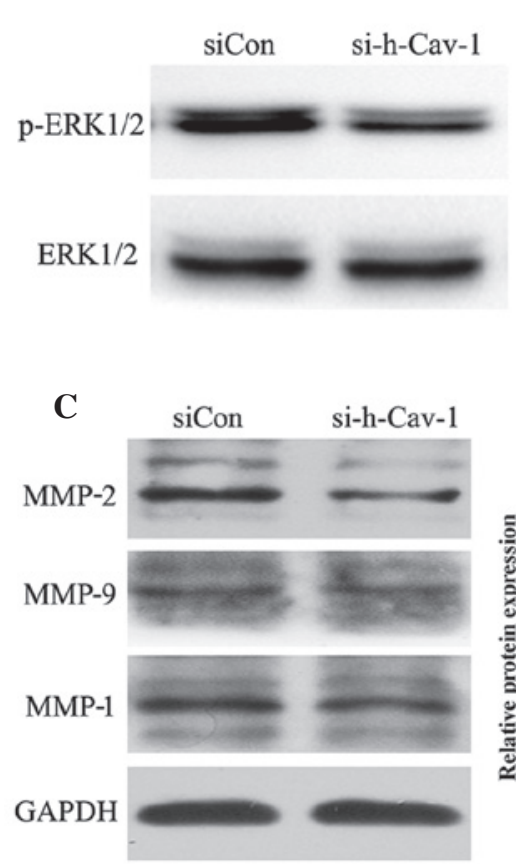

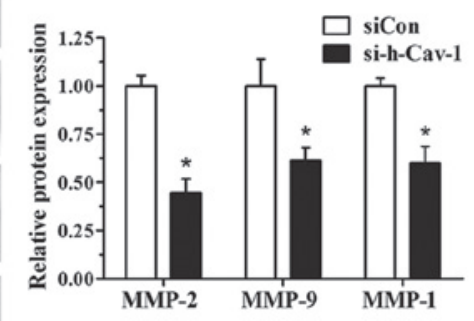

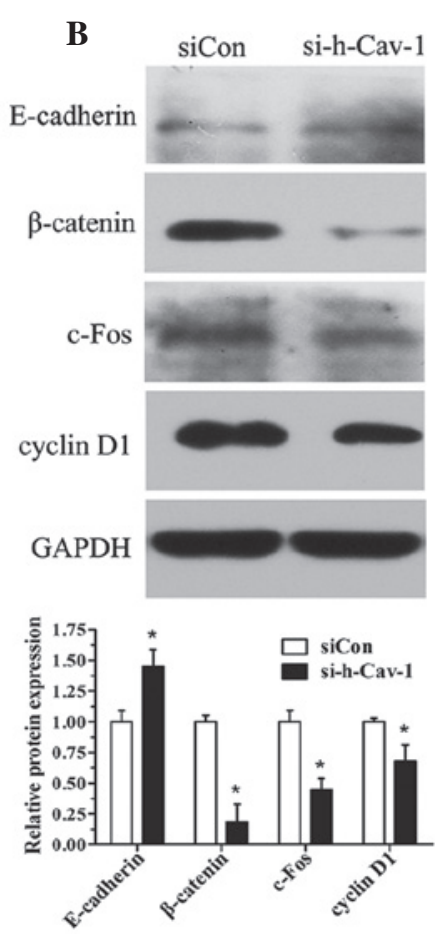

Figure 4. Effect of caveolin 1 knockdown on the activation of the ERK 1/2 pathway and the expression of proteins involved in the cell cycle, migration and invasion. Protein expression was assessed using western blot analysis. (A) Activation of the ERK1/2 pathway was inhibited by caveolin 1 knockdown. (B) Protein expression of cyclin D1, c-Fos and $\beta$-catenin was decreased by caveolin 1 knockdown, whereas E-cadherin expression was elevated. (C) Protein expression of MMPs (MMP-2, MMP-9 and MMP-1) was attenuated by caveolin 1 knockdown. Error bars represent the mean \pm standard deviation. Experiments were performed in triplicate. "P<0.05, compared with siCon. si-h-Cav-1, small interfering RNA against human caveolin 1; siCon, control siRNA; ERK1/2, extracellular signal-regulated kinase 1/2; MMP, matrix metalloproteinase.

However, caveolin 1 knockdown had a different effect on cell growth and the cell cycle in BT474 cells, resulting in a significant reduction in cell growth (Fig. 2A) associated with decreased cyclin D1 expression, and increased G0/G1 phase population and reduced $\mathrm{S}$ phase population. Furthermore, c-Fos, as well as $\beta$-catenin, has previously been demonstrated to function as a nuclear transcription factor $(23,24)$. In addition, in the present study, their expression was found to be decreased by caveolin 1 knockdown in BT474 cells (Fig. 4B).

Not only has caveolin 1 been identified as a tumorigenic activity-associated gene, but it has also been suggested that it is involved in multiple-drug resistance to chemotherapy in numerous types of carcinoma $(25,26)$. In the present study, it was demonstrated that caveolin 1 knockdown increased Dox-induced cell death in BT474 cells and therefore sensitized those cells to Dox treatment (Fig. 3C).

E-cadherin has previously been demonstrated to be important in tumor metastasis through modulating the process of cell-cell adhesion, establishment of cell polarity and cytoskeletal rearrangement (27). Downregulation of caveolin 1 has been demonstrated to be associated with a reduction in E-cadherin expression and, therefore, cell motility, as well as enhancing the metastatic ability of tumor cells (28). However, in contrast to previous studies, the inhibition of caveolin 1 in the present study resulted in an induction in the protein level of E-cadherin in BT474 cells (Fig. 4B).

In addition to E-cadherin, MMPs, a family of zinc-containing proteolytic enzymes, are important in tumor cell invasion through the degradation of proteins in the extracellular matrix and the basement membrane, for example, collagen and fibronectin. MMP-2 and MMP-9, as well as MMP-1, have been found to be important in cancer progression and metastasis (29). In the present study, it was revealed that MMP expression was downregulated by caveolin 1 knockdown in BT474 cells (Fig. 4C). In combination, these results suggest that the inhibition of migration and invasion of BT474 cells associated with caveolin 1 deprivation may be attributed to the upregulation of E-cadherin and downregulation of MMPs (MMP-2, -9, -1).

The ERK1/2 pathway is required for tumor survival (30), invasion and metastasis (31). The inhibition of cell motility by caveolin 1 knockdown in BT474 cells may therefore be attributed to the suppression of the ERK1/2 pathway (Fig. 4A).

In conclusion, the results from the present study indicate the potential capacity of caveolin 1 as a tumor promoter in BT474 cells. The role of caveolin 1 in cancer progression has been demonstrated to be controversial and complex. The present study provides novel insights into the function of caveolin 1 in breast cancer. It was demonstrated that caveolin 1 has a tumor promoting role in BT474 cells and the results suggest that caveolin 1 may be used as a metastatic marker in carcinomas. However, this requires further investigation before it may be used as a practical diagnostic and prognostic marker.

\section{Acknowledgements}

This study was supported by the National Natural Science Foundation of China (grant no. 81001171) and the Key Technologies R\&D Program of Hubei Province (grant no. 2007AA302B07). 


\section{References}

1. Siegel R, Naishadham D and Jemal A: Cancer statistics, 2013. CA Cancer J Clin 63: 11-30, 2013.

2. Shaul PW and Anderson RG: Role of plasmalemmal caveolae in signal transduction. Am J Physiol 275: L843-L851, 1998.

3. Williams TM and Lisanti MP: Caveolin-1 in oncogenic transformation, cancer, and metastasis. Am J Physiol Cell Physiol 288: C494-C506, 2005.

4. Cokakli M, Erdal E, Nart D, et al: Differential expression of Caveolin-1 in hepatocellular carcinoma: correlation with differentiation state, motility and invasion. BMC Cancer 9: 65, 2009.

5. Cerezo A, Guadamillas MC, Goetz JG, et al: The absence of caveolin-1 increases proliferation and anchorage-independent growth by a Rac-dependent, Erk-independent mechanism. Mol Cell Biol 29: 5046-5059, 2009.

6. Yang G, Truong LD, Wheeler TM and Thompson TC: Caveolin-1 expression in clinically confined human prostate cancer: a novel prognostic marker. Cancer Res 59: 5719-5723, 1999.

7. Joo HJ, Oh DK, Kim YS, Lee KB and Kim SJ: Increased expression of caveolin-1 and microvessel density correlates with metastasis and poor prognosis in clear cell renal cell carcinoma BJU Int 93: 291-296, 2004.

8. Kato K, Hida Y, Miyamoto M, et al: Overexpression of caveolin-1 in esophageal squamous cell carcinoma correlates with lymph node metastasis and pathologic stage. Cancer 94: 929-933, 2002.

9. Wu P, Wang X, Li F, Qi B, Zhu H, et al: Growth suppression of MCF-7 cancer cell-derived xenografts in nude mice by caveolin-1. Biochem Biophys Res Commun 376: 215-220, 2008.

10. Urra H, Torres VA, Ortiz RJ, et al: Caveolin-1-enhanced motility and focal adhesion turnover require tyrosine-14 but not accumulation to the rear in metastatic cancer cells. PLoS One 7: e33085, 2012.

11. Elsheikh SE, Green AR, Rakha EA, et al: Caveolin 1 and Caveolin 2 are associated with breast cancer basal-like and triple-negative immunophenotype. Br J Cancer 99: 327-334, 2008.

12. Han F, Gu D, Chen Q and Zhu H: Caveolin-1 acts as a tumor suppressor by down-regulating epidermal growth factor receptor-mitogen-activated protein kinase signaling pathway in pancreatic carcinoma cell lines. Pancreas 38: 766-774, 2009.

13. Sunaga N, Miyajima K, Suzuki M, et al: Different roles for caveolin-1 in the development of non-small cell lung cancer versus small cell lung cancer. Cancer Res 64: 4277-4285, 2004.

14. Felicetti F, Parolini I, Bottero L, et al: Caveolintumor-promoting role in human melanoma. Int J Cancer 125: 1514-1522, 2009.

15. Savage K, Lambros MB, Robertson D, et al: Caveolin 1 is overexpressed and amplified in a subset of basal-like and metaplastic breast carcinomas: a morphologic, ultrastructural, immunohistochemical, and in situ hybridization analysis. Clin Cancer Res 13: 90-101,2007.

16. Van den Eynden GG, Van Laere SJ, Van der Auwera I, et al: Overexpression of caveolin-1 and -2 in cell lines and in human samples of inflammatory breast cancer. Breast Cancer Res Treat 95: 219-228, 2006.
17. Fiucci G, Ravid D, Reich R and Liscovitch M: Caveolin-1 inhibits anchorage-independent growth, anoikis and invasiveness in MCF-7 human breast cancer cells. Oncogene 21: 2365-2375, 2002.

18. Williams TM, Medina F, Badano I, et al: Caveolin-1 gene disruption promotes mammary tumorigenesis and dramatically enhances lung metastasis in vivo. Role of Cav-1 in cell invasiveness and matrix metalloproteinase (MMP-2/9) secretion. J Biol Chem 279: 51630-51646, 2004.

19. Salatino M, Beguelin W, Peters MG, et al: Progestin-induced caveolin-1 expression mediates breast cancer cell proliferation. Oncogene 25: 7723-7739, 2006.

20. Williams TM, Lee H, Cheung MW, et al: Combined loss of INK4a and caveolin-1 synergistically enhances cell proliferation and oncogene-induced tumorigenesis: role of INK4a/CAV-1 in mammary epithelial cell hyperplasia. J Biol Chem 279: 24745-24756, 2004.

21. Williams TM, Sotgia F, Lee H, et al: Stromal and epithelial caveolin-1 both confer a protective effect against mammary hyperplasia and tumorigenesis: Caveolin-1 antagonizes cyclin D1 function in mammary epithelial cells. Am J Pathol 169: 1784-1801, 2006.

22. Boström P, Söderström M, Palokangas T, et al: Analysis of cyclins A, B1, D1 and E in breast cancer in relation to tumour grade and other prognostic factors. BMC Res Notes 2: 140, 2009.

23. Arteaga CL and Holt JT: Tissue-targeted antisense c-fos retroviral vector inhibits established breast cancer xenografts in nude mice. Cancer Res 56: 1098-1103, 1996.

24 . Wend P, Runke $\mathrm{S}$, Wend $\mathrm{K}$, et al: WNT10B/ $\beta$-catenin signalling induces HMGA2 and proliferation in metastatic triple-negative breast cancer. EMBO Mol Med 5: 264-279, 2013.

25. Selleri S, Arnaboldi F, Palazzo M, Hussein U, Balsari A and Rumio C: Caveolin-1 is expressed on multipotent cells of hair follicles and might be involved in their resistance to chemotherapy. Br J Dermatol 153: 506-513, 2005.

26. Ho CC, Kuo SH, Huang PH, Huang HY, Yang CH and Yang PC: Caveolin-1 expression is significantly associated with drug resistance and poor prognosis in advanced non-small cell lung cancer patients treated with gemcitabine-based chemotherapy. Lung Cancer 59: 105-110, 2008.

27. Tiwari N, Gheldof A, Tatari M and Christofori G: EMT as the ultimate survival mechanism of cancer cells. Semin Cancer Biol 22: 194-207, 2012.

28. Lu Z, Ghosh S, Wang Z and Hunter T: Downregulation of caveolin-1 function by EGF leads to the loss of E-cadherin, increased transcriptional activity of beta-catenin, and enhanced tumor cell invasion. Cancer Cell 4: 499-515, 2003.

29. Liu D, Guo H, Li Y, Xu X, Yang K and Bai Y: Association between polymorphisms in the promoter regions of matrix metalloproteinases (MMPs) and risk of cancer metastasis: a meta-analysis. PLoS One 7: e31251, 2012.

30. Balmanno K and Cook SJ: Tumour cell survival signalling by the ERK1/2 pathway. Cell Death Differ 16: 368-377, 2009.

31. Prasad CP, Chaurasiya SK, Axelsson L and Andersson T: WNT-5A triggers Cdc42 activation leading to an ERK1/2 dependent decrease in MMP9 activity and invasive migration of breast cancer cells. Mol Oncol 7: 870-883, 2013. 